\title{
Immunohistological characterisation of amyloid deposits in renal biopsy specimens
}

\author{
R J Fitzmaurice, C Bartley, J McClure, P Ackrill
}

\begin{abstract}
The amyloid deposits in 21 renal biopsy specimens were subjected to a detailed immunohistochemical analysis using a panel of antibodies against recognised constituents of tissue amyloid. This was a retrospective study of material originally submitted during the investigation of various renal abnormalities and studied by a routine protocol including histochemistry, electron microscopy, and immunofluorescence. The presence of an amyloid was confirmed in all 21 cases. Seventeen cases contained $P$ component and either amyloid $A$ (AA) (11 cases) or an immunoglobulin light chain associated amyloid (six cases). Four cases contained amyloid material with unusual immunohistochemical findings; one case had $A A$ and $P$-component (PC) in the interstitium, one case had $\lambda$ light chain and $\beta-2$ microglobulin, one case had $\kappa$ light chain and Clq, and one case had $\lambda$ light chains only.

It was possible, therefore, to identify precisely the amyloid constituents and thereby "type" the amyloid by immunohistochemical means. The availability of the antibodies used and their application using these techniques could simplify the confirmation of clinically suspected amyloidosis.
\end{abstract}

In haematoxylin and eosin stained paraffin wax embedded sections amyloid is recognised as amorphous hyaline and eosinophilic extracellular material. Its presence is said to be confirmed by the demonstration of applegreen birefringence on polarisation of sections stained by alkaline Congo red (ACR), ${ }^{1}$ or by finding the characteristic complex at the ultrastructural level. ${ }^{2}$

Although each type of amyloid has a particular chemical composition, ${ }^{3}$ there are two principal types. One, designated amyloid AA, is a protein of molecular weight 8500 , thought to be derived from an $\alpha-1$ - globulin serum precursor by proteolytic cleavage, and the other is derived from either $\kappa$ or $\lambda$ light chains of immunoglobulins and as a consequence is associated with B cell (immunoglobulinsecreting) tumours.

Under certain conditions, other proteins may be identified in amyloid deposits including prealbumin in heredofamilial and senile disorders, and calcitonin in medullary carcinoma of the thyroid.
There are now several published papers which confirm the presence of amyloid in formalin fixed, paraffin wax embedded tissues (including necropsy material) by immunohistological techniques using polyclonal antisera. ${ }^{4-6}$ More recently, monoclonal antibodies have been used. ${ }^{7}$ Generally, these studies have used limited panels of antisera, typically including antibodies to AA, $\kappa$, and $\lambda$ light chains, P-component, and prealbumin. One exception is a study of senile cerebral amyloidosis which used a panel of 14 antisera. ${ }^{8}$ In a small number of instances amyloid of more than one type occurring within individual deposits has been described..$^{910}$

Although the distribution of amyloid deposits and associated underlying conditions is extremely varied, the kidney is often affected, leading to impaired renal function. Immunohistological studies on localised amyloidosis of the urogenital tract, renal amyloid AA complicating hairy cell leukaemia, the prevalence of amyloidosis in a necropsy series, and characterisation of renal amyloid using antisera to AA, P-component immunoglobulin, and $\kappa$ and $\lambda$ light chains have been described in needle biopsy specimens of kidney. ${ }^{11-14}$ To our knowledge, however, there has not been an attempt to define individual constituents in renal biopsy specimens using an extended panel of antibodies. We therefore investigated the amyloid diagnosed in 21 renal biopsy specimens, using a panel of antibodies, to identify as fully as possible the constituents of the amyloid deposits.

\section{Methods}

Between 1976 and 1988, 22 patients had renal amyloidosis diagnosed by biopsy. In 21 cases there was sufficient material available to perform the additional studies detailed herein. Patient details are given in table 1.

The original renal biopsy specimen had been divided into three portions. One had been formalin fixed and embedded in paraffin wax. Sections ( $4 \mu \mathrm{m}$ thick) had been stained with haematoxylin and eosin, Congo red, periodic acid Schiff, and Gomori's silver stains. Another had been frozen, and cryostat sections had been stained using a one-step fluorescein labelled antibody method. The third had been post-fixed in glutaraldehyde; thin sections had been stained with uranyl acetate and lead citrate and examined with an AE1 801 electron microscope.

In the additional study serial sections $(4 \mu \mathrm{m})$ of formalin fixed, paraffin wax embed- 
Table 1 Diagnostic biopsy report

\begin{tabular}{|c|c|c|c|c|c|}
\hline $\begin{array}{l}\text { Case } \\
\text { No }\end{array}$ & Age/Sex & Diagnosis & $\begin{array}{l}\text { Light } \\
\text { microscopy }\end{array}$ & $\begin{array}{l}\text { Electron } \\
\text { microscopy }\end{array}$ & Immunofluorescence \\
\hline $\begin{array}{l}1 \\
2 \\
3 \\
4 \\
5\end{array}$ & $\begin{array}{l}66 \mathrm{~F} \\
69 \mathrm{~F} \\
59 \mathrm{~F} \\
40 \mathrm{M} \\
58 \mathrm{~F}\end{array}$ & $\begin{array}{l}\text { Rheumatoid arthritis } \\
\text { Nephrotic syndrome } \\
\text { Rheumatoid arthritis } \\
\text { Nephrotic syndrome } \\
\text { Nephrotic syndrome/ }\end{array}$ & $\begin{array}{l}\text { G, BV, T } \\
\text { G, BV } \\
\text { G, BV,T, I } \\
\text { G, BV, T }\end{array}$ & $\begin{array}{l}+ \\
+ \\
+ \\
+\end{array}$ & $\begin{array}{l}- \\
- \\
\overline{\text { IgM, C3 }}\end{array}$ \\
\hline $\begin{array}{l}6 \\
7 \\
8 \\
9\end{array}$ & $\begin{array}{l}57 \mathrm{M} \\
56 \mathrm{~F} \\
78 \mathrm{M} \\
65 \mathrm{~F}\end{array}$ & $\begin{array}{l}\text { rheumatoid arthritis } \\
\text { Nephrotic syndrome } \\
\text { Rheumatoid arthritis } \\
\text { Nephrotic syndrome } \\
\text { Rheumatoid arthritis/ }\end{array}$ & $\begin{array}{l}\text { G, BV } \\
\text { G, PT, I } \\
\text { G, BV, PT, I } \\
\text { G, BV, PT, I }\end{array}$ & $\begin{array}{l}- \\
+ \\
+ \\
+\end{array}$ & $\begin{array}{l}\text { IgG, IgA, IgM, C3, fibrin } \\
\text { C3, fibrinogen } \\
\text { Fibrin } \\
\text { Fibrinogen }\end{array}$ \\
\hline $\begin{array}{l}10 \\
11 \\
12 \\
13\end{array}$ & $\begin{array}{l}74 \mathrm{~F} \\
64 \mathrm{~F} \\
50 \mathrm{~F} \\
51 \mathrm{~F}\end{array}$ & $\begin{array}{l}\text { nephrotic syndrome } \\
\text { Chronic renal failure } \\
\text { Acute renal failure } \\
\text { Rheumatoid arthritis } \\
\text { Hypertrophic } \\
\text { cardiomyopathy/chronic- } \\
\text { renal failure }\end{array}$ & $\begin{array}{l}\text { G, BV, I } \\
\text { G, BV } \\
\text { G } \\
\text { G, BV } \\
\text { G, BV, T, I }\end{array}$ & $\begin{array}{l}+ \\
\text { N/A } \\
+ \\
\text { N/A } \\
\text { N/A }\end{array}$ & $\begin{array}{l}- \\
- \\
\overline{-} \\
\overline{I g G}, \mathrm{IgA}, \mathrm{IgM}, \text { fibrin, C3, Clq }\end{array}$ \\
\hline $\begin{array}{l}14 \\
15 \\
16 \\
17 \\
18 \\
19\end{array}$ & $\begin{array}{l}72 \mathrm{M} \\
72 \mathrm{M} \\
51 \mathrm{~F} \\
51 \mathrm{~F} \\
69 \mathrm{~F} \\
62 \mathrm{~F}\end{array}$ & $\begin{array}{l}\text { Chronic renal failure } \\
\text { Chronic renal failure } \\
\text { Rheumatoid arthritis } \\
\text { Acute renal failure } \\
\text { Polymyalgia rheumatica } \\
\text { Diabetes mellitus with } \\
\text { proteinuria }\end{array}$ & $\begin{array}{l}\text { BV } \\
\text { G, BV } \\
\text { BV, I } \\
\text { G, BV } \\
\text { G, BV } \\
\text { G, BV, PT, I }\end{array}$ & $\begin{array}{l}- \\
+ \\
\mathbf{N} / \mathbf{A} \\
+ \\
+ \\
+ \\
+\end{array}$ & $\begin{array}{l}- \\
\text { IgG, IgA, C3 } \\
- \\
\text { IgM, C3, Clq } \\
\text { IgG, IgM, C2, C1q, fibrin }\end{array}$ \\
\hline $\begin{array}{l}20 \\
21 \\
\end{array}$ & $\begin{array}{l}53 \mathrm{M} \\
50 \mathrm{M} \\
\end{array}$ & $\begin{array}{l}\text { proteinuria } \\
\text { Chronic renal failure } \\
\lambda \text { chains urine }\end{array}$ & $\begin{array}{l}\mathrm{G}, \mathrm{BV}, \mathrm{PT}, \mathrm{I} \\
\overline{\mathrm{G}}, \mathrm{BV}\end{array}$ & $\begin{array}{l}+ \\
+ \\
+\end{array}$ & $\begin{array}{l}\mathrm{Clq} \\
\mathrm{IgG}, \mathrm{IgA}, \mathrm{IgM}, \mathrm{C} 3, \mathrm{Clq}\end{array}$ \\
\hline
\end{tabular}

^Positive for Congo red staining.

G-glomeruli, BV-blood vessels, T-tubules, I-interstitium, PT-peritubular.

++ amyloid material identified ultrastructurally

+ amyloid material identified
- no fibrillar material seen.

ded tissues were stained with haematoxylin and eosin, alkaline Congo red, and alkaline Congo red with potassium permangante as a pretreatment. ${ }^{15}$ Sections were also immunostained with the rabbit anti-human polyclonal antibodies detailed in table 2 , using a conventional peroxidase-antiperoxidase technique. Negative controls were performed using no primary antiserum. Positive controls for amyloid $\mathrm{A}, \kappa$, and $\lambda$ light chains were available in the form of representative blocks from known cases of amyloid $A$ and systemic amyloid in $\kappa$ and $\lambda$ light chain multiple myeloma, respectively. Although enhancement of amyloid immunostaining has been described, we did not find this necessary in our study.

All sections were examined by two observers independently and the results compared and pooled. Disagreements as to positivity and anatomical site were resolved by discussion.

\section{Results}

The results are shown in tables 1 and 3. In all 21 cases amyloid was positively identified by Congo red staining and characteristic applegreen birefringence in polarised light. In 17 of the cases amyloid deposits could be definitely identified as containing either AA amyloid (11 cases), or immunoglobulin light chain associated amyloid (six cases: five $\lambda$, one $\kappa$ ). The deposits in these cases also contained P-component.

The unusual cases were as follows: (i) case 18 , which contained a small amount of $A A$ and $P$-component in the interstitium (the specimen consisted solely of tubules); (ii) case 19, which contained $\lambda$ light chains in glomeruli and also $\beta-2$ microglobulin focally within glomeruli; (iii) case 20 , in which weakly positive staining for $\kappa$ light chains was shown in occasional glomeruli and their capsules (Clq was also shown in capsules and glomeruli of this case, a unique finding in the series); and (iv) case 21 , which contained $\lambda$ light chains only, in glomeruli and blood vessels.

Thyroglobulin, calcitonin, and C3c were not identified immunohistochemically in any of the sections.

In 14 cases the presence of amyloid material was confirmed ultrastructurally. Amyloid was only seen electron microscopically in those cases which could be definitely subclassified on immunohistological analysis. In a further two cases examined fibrillar material was not identified.

Figures 1 and 3 include the results of immunostaining.

\section{Discussion}

Although amyloid has uniform light microscopical and ultrastructural appearances, it is not a homogeneous chemical entity. Ultra-

Table 2 Antibody dilutions and distributors

\begin{tabular}{lll}
\hline Antibody & Dilutions & Distributors \\
\hline AA & $1 / 500$ & Calbiochem (Cambridge \\
& & Biosciences, Cambridge) \\
P-Component & $1 / 250$ & \\
B-2 microglobulin & $1 / 500$ & \\
$\kappa$ light chain & $1 / 5000$ & \\
$\lambda$ light chain & $1 / 5000$ & \\
Fibrinogen & $1 / 2500$ & Dako Ltd, High Wycombe, \\
Pre-albumin & $1 / 500$ & Bucks \\
& & \\
IgA & $1 / 2500$ & \\
IgM & $1 / 2500$ & \\
IgG & $1 / 2500$ & \\
C3c & $1 / 500$ & \\
Clq & $1 / 500$ & \\
Thyroglobulin & $1 / 5000$ & \\
Calcitonin & $1 / 500$ & \\
\hline
\end{tabular}


Table 3 Histochemistry and immunostaining

\begin{tabular}{|c|c|c|c|c|c|c|c|c|c|c|c|c|c|}
\hline $\begin{array}{l}\text { Case } \\
\text { No }\end{array}$ & $\begin{array}{l}\text { Alkaline } \\
\text { Congo } \\
\text { red }^{\star}\end{array}$ & KMm04† & $\begin{array}{l}P- \\
\text { component }\end{array}$ & & $A A$ & $\begin{array}{l}\text { B-2 } \\
\text { micro- } \\
\text { globulin }\end{array}$ & $\lambda$ & $\kappa$ & Fibrinogin & $\begin{array}{l}\text { Pre- } \\
\text { albumin }\end{array}$ & $\operatorname{Ig} A$ & $I g G$ & $C 1 q$ \\
\hline 1 & G, BV & Inhibited & G, BV & & $\mathbf{G}, \mathbf{B V}$ & - & - & - & $\mathrm{G}, \pm \mathrm{I}, \pm$ & $T$ & $\mathrm{~T}, \mathrm{I}$ & $\mathbf{T} \pm$ & - \\
\hline 2 & & Persists & G, & I & - & - & G, BV, I & - & $-1-1$ & - & - & - & - \\
\hline 3 & $\bar{G}$ & Inhibited & G & & G & - & - & - & - & - & - & - & - \\
\hline 4. & G, BV & Inhibited & $\mathbf{G}$ & & G, BV & - & - & - & - & - & - & - & - \\
\hline 5 & $\mathbf{G}, \quad \mathbf{T}$ & Inhibited & & I & G, BV & - & I & G, T & - & - & - & - & - \\
\hline 6 & G, $\quad T$ & Persists & & & - & - & - & G, T & - & - & - & - & - \\
\hline 7 & G, BV & Inhibited & G, BV & & G, BV & - & - & - & - & - & - & - & - \\
\hline 8 & G, BV & Inhibited & G, BV & & & - & G, BV & - & - & - & - & - & - \\
\hline 9 & G, BV, T & Inhibited & G, BV, T & & G, & $\mathbf{B V}, \mathbf{T} \pm$ & - & - & $G, \pm I \pm$ & - & - & - & - \\
\hline 10 & G, BV & Persists & G, BV & & & - & G, BV & - & - & - & - & - & - \\
\hline 11 & G, BV & Inhibited & - & & $\mathbf{G}, \mathbf{B V}$ & - & - & - & - & - & - & - & - \\
\hline 12 & BV, T & Inhibited & - & & BV, T & - & - & - & - & - & - & - & - \\
\hline 13 & $\mathbf{G}, \mathbf{B V}, \mathbf{T}$ & Persists & G, BV, T & & - & - & - & $G, \pm T, \pm I$ & - & - & - & - & - \\
\hline 14 & & & BV, & I & - & G, T & - & - & - & - & - & - & \\
\hline 15 & G, BV & Inhibited & G, BV, & I & G, BV, I & - & - & - & - & - & - & - & - \\
\hline 16 & & & - & & $\mathrm{I} \pm$ & - & - & - & - & - & - & - & - \\
\hline 17 & G, BV, T & Inhibited & G, & & $\mathrm{G}, \mathrm{BV}, \mathrm{T}$ & - & - & - & G, BV, T & - & - & - & - \\
\hline 18 & - & - & G & & G, BV & - & - & - & - & - & - & - & - \\
\hline 19 & G & Persists & I & & - & G & G, & - & - & - & - & - & - \\
\hline 20 & G, BV & Persists & $\mathbf{G}_{ \pm, \mathbf{I}}$ & & - & $\mathbf{T}$ & BV & - & - & - & - & - & G \\
\hline 21 & G, BV & - & - & & - & - & G, BV & - & - & - & - & - & - \\
\hline
\end{tabular}

^Sites positive by light microscopy.

tKMm04-Alkaline Congo red with potassium permanganate pretreatment. \pm present focally.

Figure 1A Case 1: section (viewed in polarised light) from a case of amyloid $A$. Amyloid deposits are well localised (alkaline Congo red).

Figure 1B Case 1: Same field as 1 A. Alkaline Congo red with potassium permanganate

pretreatment.

Examination in polarised light shows loss of much of the staining of the amyloid material (alkaline Congo red). structural observation of amyloid deposits show a complex, predominantly formed $(90 \%)$ of irregularly arranged, non-branching fibrils $(7.5-10 \mathrm{~nm}$ in diameter), which are invariably associated with $\mathrm{P}$-component, a pentagonal glycoprotein identical with an $\alpha-1$-glycoprotein found in normal serum. It is the aggregation of the amyloid fibrils into a cross B-pleated sheet configuration that is responsible for the optical characteristics on polarisation.

We included the potassium permanganate pretreatment method as an aid to confirming the presence of AA as it is supposed to abolish alkaline Congo red staining when this is caused by AA. There are doubts, however, as to its specificity. Taken with the non-specific light and electron microscopic appearances, this means that for full characterisation of amyloid a panel of antibodies to the various possible components have to be used.

The most extensive series of immunohistological studies have been performed in the neurodegenerative diseases in the central nervous system, and recently new amyloid components have been identified. ${ }^{16}$

In our study, 17 cases contained amyloid deposits, the immunohistological staining reactions of which were unequivocal, and a definite subtype could therefore be stated. We identified $P$-component in 16 cases, in a distribution corresponding to amyloid, but we did not identify $\mathrm{P}$-component in isolation. While faint

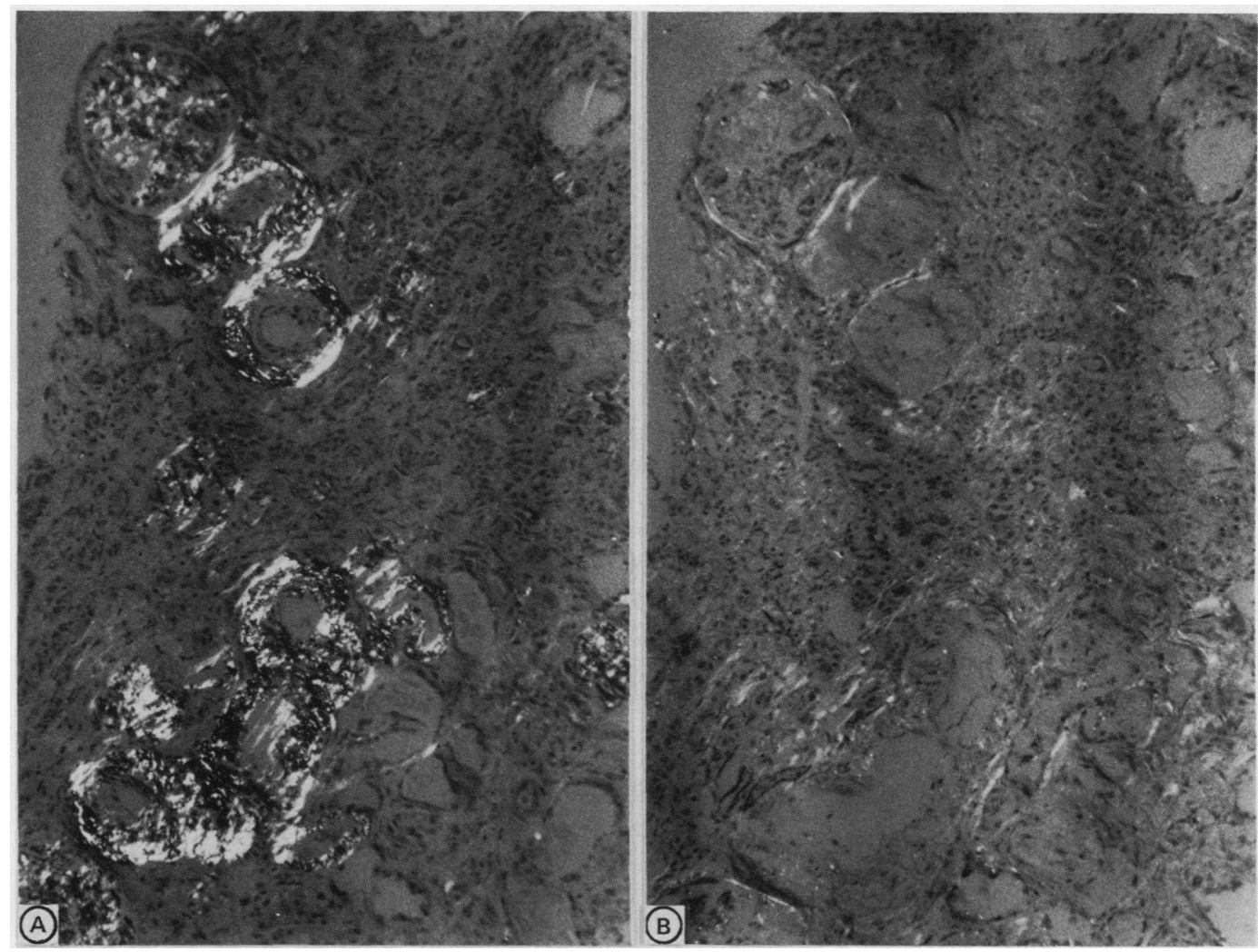


Figure 2 Case 4: immunolocalisation of amyloid $A$ deposits in glomerulus and small artery $(P A P)$.

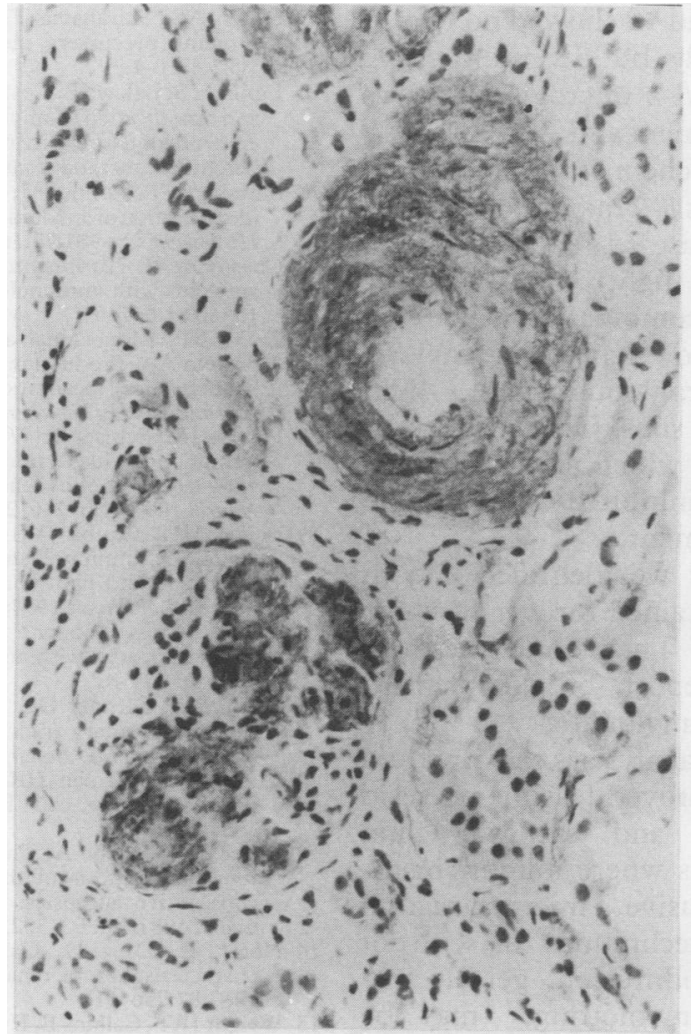

staining of P-component was seen in normal sites (glomerular basement membrane and certain vessels), this was of no consequence compared with that in the amyloid deposits, was outside the amyloid deposits, and was therefore not specifically recorded.

$\beta-2$ microglobulin was seen in four cases, always associated with other amyloid components, although it is a well recognised form of amyloidosis in patients receiving dialysis ${ }^{17}$ in whom it may be systemic, or responsible for carpal tunnel syndrome, or tumoral amyloidosis of bone and intestinal infarction. Two of our patients were not receiving dialysis, indicating that $\beta-2$ microglobulin deposition is not always related to this form of treatment.

We identified not only cases of light chain amyloid but also a case (case 5) of AA in association with $\kappa$ light chains in a similar distribution. The staining in this case leads us to believe that this is a combined form of amyloid. In this case, as would be expected, $\lambda$ light chains were also present, but these were located in the interstitium and were not associated with the amyloid deposits. Kappa light chain disease has been described as a complication of multiple myeloma in three cases, but in only one of these, and in the kidney, was there an association between amyloid deposition and $\kappa$ light chains. ${ }^{18}$ In only one of our cases (case 1) did we identify immunoglobulins but failed to show $\kappa$ and $\lambda$ light chains. This may have been due to an inability of the antibodies to discriminate the light chains from the whole molecule in these small deposits, or possibly due to a masking effect. We were also unable to confirm by immunohistochemistry (table 3 ) the presence of some immunoglobulins and $\mathrm{Clq}$ that had been initially shown using immunofluorescence (table 2).

Some of our cases were difficult to subtype outright. One of these (case 16) consisted solely of tubules. In the original examination, however, Congo red positivity had been present in blood vessels and interstitium. We identified focally AA only within the interstitium and therefore feel that this is probably
Figure $3 A$ Case 5: amyloid $A$ deposits in two glomeruli (PAP).

Figure 3B Case 5: Same field as $4 A$ showing coexistent presence of $\kappa$ light chains in the same two glomeruli revealed by immunostaining (PAP) (Nomarski phase).

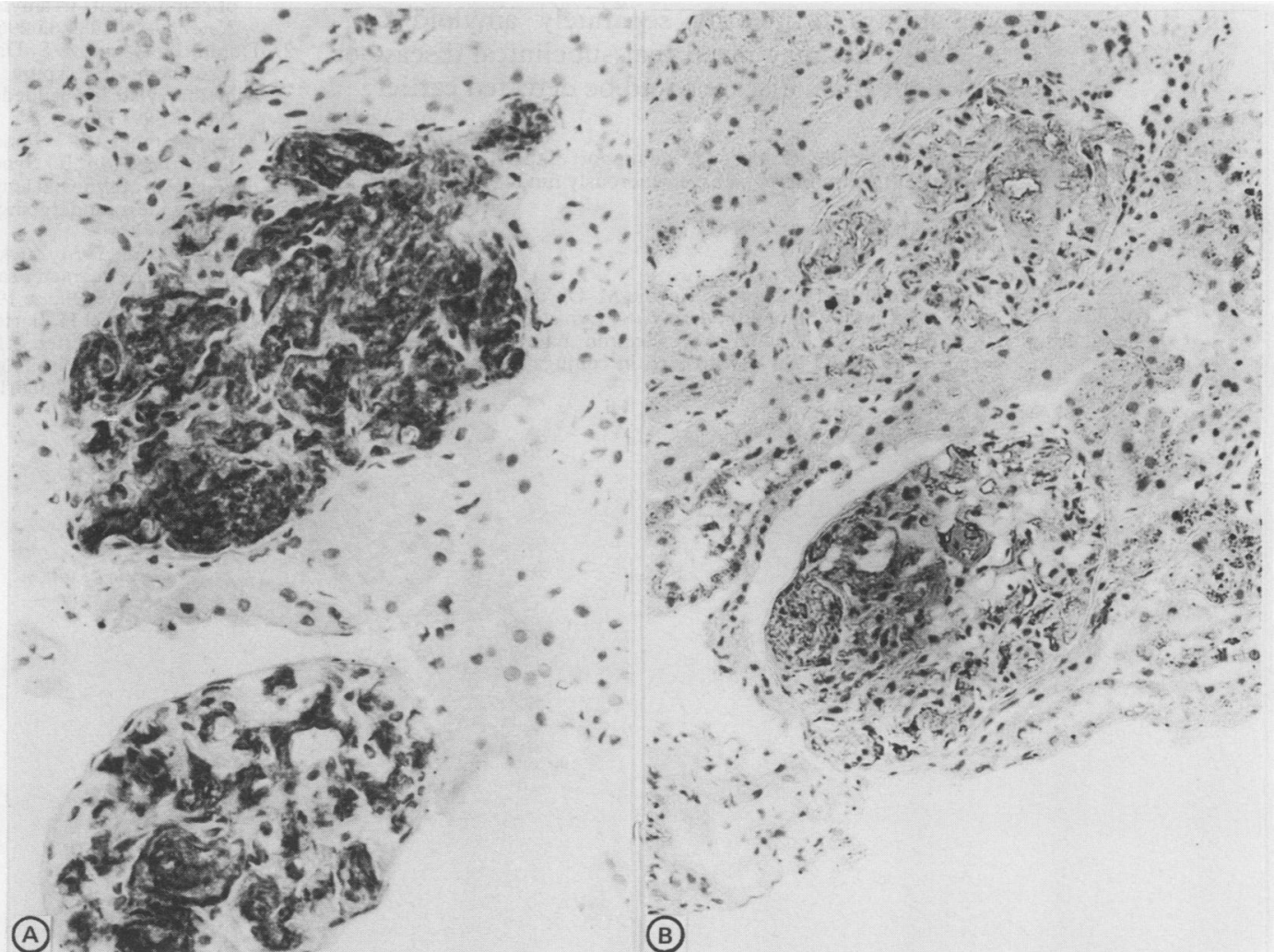


of AA type. Cases 14 and 18 showed no Congo red material in our study, but definite staining for P-component and $\beta-2$ microglobulin was seen in 14 and $P$-component and $A A$ in 18. As a result of immunohistochemistry these could therefore be classified as $\beta-2$ microglobulin and AA, respectively. Case 19 showed $\beta-2$ microglobulin and $\lambda$ light chains in the glomeruli, an unusual combination which was thought to be a probable $\lambda$ light chain amyloid, and case $20, \beta-2$ microglobulin and $\lambda$ light chains, but in differing sites. Case 8 showed $\lambda$ light chain amyloid in which alkaline Congo red staining had been inhibited by potassium permanganate pretreatment.

In one of our cases we identified Clq in glomeruli which also stained for $\lambda$ light chain and $\beta-2$ microglobulin. This is only the third immunohistological report of complement components shown in amyloid. ${ }^{1920}$

Immunohistological analysis is sensitive and reliable and has been proved feasible on resin embedded sections, ${ }^{21}$ and synovial fluid sediment, ${ }^{22}$ but in cases where immunohistochemistry is inconclusive, microextraction with immune diffusion techniques ${ }^{23}$ or, with dot immunoassay, immunodiffusion, gel electrophoresis, and Western blotting, ${ }^{24}$ may be useful.

We have shown that in most cases, using a combination of histochemistry and immunohistochemistry on routinely processed tissues, it is possible not only to identify the presence of amyloid but also to distinguish individually the constituents of the deposits. These techniques could therefore be useful in the assessment of biopsy specimens where amyloid has been diagnosed or would be expected clinically, or, where histologically suspicious deposits have proved Congo red negative. The possibility of obtaining this increased sensitivity and the ability to identify separately amyloid constituents may mean that subclinical disease or light chain disease could be detected earlier.

We gratefully acknowledge the support of the South Mancheste Health Authority who have generously funded this project.

1 Puchtler H, Sweat F, Levine M. On the binding of Congo Red by amyloid. J Histochem Cytochem 1962;10:355-64.

2 Paul WE, Cohen AS. Electron microscopic studies of amyloid fibrils with ferritin conjugated antibody. $A m \mathrm{~J}$ Pathol 1963;43:721-38.
3 Cohen AS, Shirahama T, Sipe JD, Skinner M. Amyloid proteins, precursers, mediator and enhancer. Lab Invest 1983;48:1-4

4 Fujihara S, Balow JE, Costa JC, Glenner GG. Identification and classification of amyloid in formalin fixed, paraffin wax embedded tissue sections by the unlabelled immunoperoxidase method. Lab Invest 1980;43:358-65.

5 Shirahama T, Skinner M, Cohen AS. Immunocytochemical identification of amyloid in formalin fixed paraffin sections. Histochemistry $981 ; 72: 161-71$.

6 Chastonay P, Hurlimann J. Characterisation of different amyloids with immunological techniques. Path Res Pract 1986;181:657-63.

7 Linke RP. Monoclonal antibodies against amyloid fibril protein AA. Production, specificity and use for immunoprotein AA. Production, specificity and use for immuno-
histochemical localisation and classification of AA type histochemical localisation and classification of AA

8 Powers JM, Schlaepfer WW, Willingham MC, Hall BJ. An immunoperoxidase study of senile cerebral amyloidosis with pathogenetic considerations. J Neuropathol Exp Neurol 1981;40:592-612.

9 Feiner HD, Chuba JV, Marion P, Debra B, Cohen D, Gallo GR. Immunohistologic characterisation of amyloid $A$ protein and light chain amyloid in kidney and other tissues. Lab Invest 1984;50:20A.

10 Alpers CE, Hopper J, Biava CG. Light chain glomerulopathy with amyloid-like deposits. Hum Pathol glomerulopathy

11 Fujihara S, Glenner GG. Primary localised amyloidosis of the genitourinary tract: immunohistochemical study on eleven cases. Lab Invest 1981;44:55-60.

12 Linder J, Silberman HR, Croker BP. Amyloidosis complicating hairy cell leukaemia. Am J Clin Pathol 1982;78:864-7.

13 Lofberg $\mathrm{H}$, Grubb A, Thysell $\mathrm{H}$, et al. The prevalence of renal amyloidosis of the AA type in a series of 1,158 consecutive autopsies. Acta Pathol Microbiol Immunol Scand 1987;95:297-302.

14 Noel LH, Droz D, Ganeval D. Immunohistochemical characterisation of renal amyloidosis. Am J Clin Pathol 1987;87:756-61.

15 Wright JRT, Calkins E, Humphrey RL. Potassium permanganate reaction on amyloidosis: an histologic method to ganate reaction on amyloidosis: an histologic method to
assist in differentiating forms of this disease. Lab Invest assist in differen
$1977 ; 36: 274-81$

16 Roberts GW, Lofthouse R, Allsop D, et al. Central Nervous System proteins in neurodegenerative disease. Neurology 1988;38:1534-40.

17 McClure J, Bartley CJ, Ackrill P. Carpal tunnel syndrome caused by amyloid containing beta 2 microglobulin: a new amyloid and a complication long term haemodialysis. $A n n$ Rheum Dis 1986;45:1007-11.

18 Kirkpatrick CJ, Curry A, Galle J, Melzner I. Systemic kappa light chain deposition and amyloidosis in multiple myeloma: novel morphological observations. Histopathology 1986;10:1065-76.

$19 \mathrm{Katz}$ A, Weicker-Thorne J, Painter RH. The relationship of a serum protein $\mathrm{Clt}$, to a common non-fibrillar constituent a serum protein Clt, to a common non-fibrillar constituent
of amyloid ( $\mathrm{P}$ component) as revealed by immunohistoof amyloid (P component) as revealed by imm
chemical studies. Am J Pathol 1977;88:679-98.

20 Ishii T, Haga S. Immuno-electron-microscopic localisation of complements in amyloid fibrils of senile plaques. Acta Neuropathol 1984;63:296-300.

21 Donini U, Casanova S, Dal-Bosco F, Linke RP. Immunohistochemical typing amyloid on hydroxyethylmethacrylate-embedded renal biopsies. Appl Pathol 1984;2:299-307.

22 Munoz-Gomez J, Gomez-Perez R, Sole-Arques $M$, Llopart-Buisan E. Synovial fluid examination for the diagnosis of synovial amyloidosis in patients with chronic diagnosis of synovial amyloidosis in patients with chronic 1987;46:324-6.

23 Pras M, Schubert M, Zucker-Franklin D, Rimon A, Franklin EC. The characterisation of soluble amyloid prepared in EC. The characterisation of soluble

24 Linke RP, Hampl H, Bartel-Schwarze S, Eulitz M. Beta 2microglobulin, different fragments and polymers thereof in synovial amyloid in long-term haemodialysis. Biol Chem Hoppe Seyler 1987;368:137-44. 